doi:10.12662/2359-618xregea.v9i3.p221-239.2020

\title{
ASSESSORAMENTO SECRETARIAL ASSOCIADO À GESTÃO DA INFORMAÇÃO NO PROCESSO DE AVALIAÇÃO DA CAPES
}

\author{
SECRETARIAL ADVISORY ASSOCIATED WITH \\ INFORMATION \\ MANAGEMENT IN THE CAPES ASSESSMENT \\ PROCESS
}

\section{RESUMO}

Os Programas de Pós-Graduação têm ampliado sua relevância na contribuição ao desenvolvimento científico e tecnológico do Brasil. Nessa direção, o reconhecimento e/ou a manutenção de um Programa de Pós-Graduação é submetido ao processo de avaliação da CAPES, que demanda uma série de informações, as quais necessitam ser efetivamente gerenciadas. Diante disso, objetiva-se verificar como o assessoramento secretarial, associado à gestão da informação, pode colaborar no processo de avaliação da CAPES, no Programa de Pós-Graduação em Engenharia de Automação e Sistemas (PPGEAS). Para tanto, utilizaram-se a abordagem qualitativa, por intermédio de um estudo de campo, as pesquisas bibliográfica, documental e a observação participante. Os resultados demonstraram contribuição do assessoramento, alinhado à gestão de informações no PPGEAS, principalmente, àquelas relacionadas às atividades que compõem os indicadores do Sistema de Avaliação da CAPES. Concluiu-se haver possibilidade para uma concreta atuação do secretário executivo, fundamentalmente, nos períodos transitórios da equipe da coordenação, quando o gerenciamento contínuo das informações necessita de suporte qualificado.

Palavras-chave: Gestão da Informação. Sistema de Avaliação. Pós-Graduação. Assessoramento. Secretário Executivo.

cibele.martins@ufsc.br

Doutora em Administração.

Professora da Universidade

Federal de Santa Catarina.

Florianópolis $-S C-B R$.

Luci Mari Aparecida Rodrigues luci.mari@ufsc.br

Doutoranda em Administração na Universidade Federal de Santa Catarina. Florianópolis $S C-B R$.

\section{ABSTRACT}

The Graduate Programs have increased their relevance in contributing to the scientific and technological development of Brazil. In this sense, the recognition and / or maintenance of a Graduate Program is submitted to the CAPES evaluation process, which requires a series of information that requires an efectively management. Based on that, this research aims to verify how the se- 
cretarial advisory, associated with information management, can collaborate in the CAPES evaluation process, in the Automation and Systems Engineering (PPGEAS) Postgraduate Program. For this, the qualitative approach was used, combined with a survey. As a date, bibliographic, documentary research, and participant observation were used. The results demonstrated the contribution of the advisory services, in line with the activities that compose the CAPES evaluation process indicator. It was concluded that there is a possibility for a concrete performance by the executive secretary, fundamentally, in the transitional periods of the coordination team, when the continuous management of information needs qualified support.

Keywords: Information Management. Evaluation System. Graduate Program. Advisory. Executive Secretary.

\section{INTRODUÇÃO}

A Pós-Graduação tem ampliado sua relevância, em termos de contribuição para com o desenvolvimento científico e tecnológico do Brasil (Coordenação de Aperfeiçoamento de Pessoal de Nível Superior (CAPES) (CAPES, 2018a). Nesse sentido, o acompanhamento do desempenho das Instituições de Ensino Superior (IES) vem, por anos, obtendo destaque perante os objetivos de desenvolvimento econômico e social de diversos países (MACCARI et al., 2014).

No caso dos Programas de Pós-Graduação (PPGs) brasileiros vinculados a tais instituições, isso ocorre por meio do Sistema de Avaliação da Pós-Graduação, que é gerenciado pela Coordenação de Aperfeiçoamento de Pessoal de Nível Superior (CAPES, 2018b). A avaliação dos cursos stricto sensu ocorre com base nos indicadores do sistema de avaliação da CAPES.

No âmbito do Sistema e por meio da Plataforma Sucupira, ao final do processo, os cursos recebem notas que variam de 1 a 7 e, na sequência, são ranqueados, a partir da nota 3 , fato que implica o reconhecimento ou a sua manutenção junto ao Conselho Nacional de Educação - CNE/MEC e recomendação da CAPES (CAPES, 2018b). Esse cenário engloba 4.394 PPGs reconhecidos pela CAPES no país (CAPES, 2018a), dos quais 117 são ofertados pela Universidade Federal de Santa Catarina (UFSC) (CAPES, 2018a).

Como parte integrante dos PPGs da UFSC, destaca-se o Programa de Pós-Graduação em Engenharia de Automação e Sistemas (PPGEAS), vinculado ao Centro Tecnológico (CTC), local escolhido para o desenvolvimento desta pesquisa. De modo geral, o PPGEAS possui caráter abrangente e multidisciplinar, no qual circulam diversas informações, tanto no âmbito acadêmico como no administrativo.

Assim, tomou-se como premissa, nesse contexto, que o gerenciamento dessas informações, bem como dos dados que as suportam podem refletir na qualidade e na produtividade do programa, em face do atendimento dos indicadores do sistema de avaliação da CAPES. Vale ressaltar que as coordenadorias dos PPGs contam com o apoio de uma equipe formada pelo corpo docente, na constituição de comissões e colegiados (não fixas) e pelo pessoal de apoio administrativo (fixos), para suporte em todas as demandas do programa, inclusive, a gestão da informação.

Diante disso, considerando essa última atuação, este estudo pretende discutir a atuação do secretário executivo na gestão administrativa das secretarias dos PPGs. O proposto ancora-se, principalmente, em uma das competências que esse profissional desenvolve, que é a de "[...] gerenciamento de informações, assegurando uniformidade e referencial para diferentes usuários." (BRASIL, 2005, online) e pelo seu destaque quando atua no assessoramento (MONTEIRO; CECATTO; GARDIN, 2015).

Nesse sentido, Monteiro, Ceccatto e Gardin (2015) apontam que esse profissional atua "para que as decisões tomadas sejam eficazes aliando, assim, à gestão da informação às atividades rotineiras de trabalho." (MONTEIRO; CECATTO; GARDIN, 2015, p. 143). Nessa direção, tem-se o fato de que a informação é um recurso fundamental nas organizações e que, se 
não gerida de forma apropriada, pode constituir um problema quando são encontradas dificuldades em seu volume (armazenamento), alcance (universo amplo) e circulação (chegada nos setores de interesse) (ARAÚJO, 2014).

Nessa perspectiva, dado que a coordenação dos PPGs não tem caráter fixo, fato que pode levar à perda de informação na transição de mandatos, tem-se que o gerenciamento da informação e o assessoramento são competências secretariais e, ainda, que o secretário executivo poderia atuar de forma "permanente" no ambiente ora explorado, este estudo questiona como o assessoramento secretarial, associado à gestão da informação, pode colaborar no processo de avaliação da CAPES, no Programa de Pós-Graduação em Engenharia de Automação e Sistemas (PPGEAS)?

Por meio da indagação ora proposta, tem-se como objetivo deste estudo verificar como o assessoramento secretarial, associado à gestão da informação, pode colaborar no processo de avaliação da CAPES, no Programa de Pós-Graduação em Engenharia de Automação e Sistemas (PPGEAS). Observa-se que, para fins de delimitação do estudo, escolheu-se um local específico, no qual foi averiguada a necessidade de profissionais capacitados para atender às demandas existentes, relacionadas ao assessoramento e à manutenção das informações do programa, diante dos resultados que ele deseja alcançar na avaliação da CAPES.

Justifica-se a escolha do profissional de secretariado pelas competências já mencionadas e pela possibilidade de poder ser ele um ator fixo naquele setor (elemento fundamental para que a informação não se "perca"), visto que os coordenadores não o são. Considera-se, ainda, que esta pesquisa contribui, como fonte bibliográfica, para futuros trabalhos, relacionados à capacidade de assessoramento do secretário e à colaboração deste com os setores gerenciais no contexto da gestão da informação.

Ressalta-se que, na busca por contribuições científicas referentes ao papel do sujeito secretário como assessor e gestor da informação no contexto ora explorado, foram encontra- dos trabalhos de relevância, porém em número reduzido e com indicação de necessidade de se ampliar as pesquisas sobre a temática. Nesse sentido, acredita-se que a possibilidade de verificar de forma teórica-empírica o proposto neste estudo contribui para com o desenvolvimento do campo de atuação secretarial.

Diante do exposto, este estudo está estruturado em cinco seções. A introdução, ora apresentada, que trata do tema proposto, problemática, objetivos, justificativa e estrutura; o referencial teórico retrata os autores que tratam sobre a pós-graduação brasileira e o seu sistema de avaliação, gestão da informação e o profissional de secretariado e a assessoria executiva.

Na sequência, passa-se aos Procedimentos Metodológicos utilizados para desenvolver a pesquisa, aos resultados e discussões, conforme os objetivos propostos e às considerações finais, retornando-se os objetivos estabelecidos e proposição de sugestões para futuras pesquisas. Por fim, têm-se as referências utilizadas para o embasamento teórico neste estudo.

\section{REFERENCIAL TEÓRICO}

\subsection{A PÓS-GRADUAÇÃO BRASILEIRA E SEU SISTEMA DE AVALIAÇÃO}

A criação dos Programas de Pós-Graduação stricto sensu é considerada recente no Brasil. O início ocorreu em 1965, por meio do parecer no 977 (Parecer Newton Sucupira), aprovado pelo Conselho Federal de Educação (CFE) (SANTOS et al., 2015). Os programas de Pós-Graduação são divididos em dois grandes grupos: lato sensu e stricto sen$s u$. O primeiro compreende apenas os cursos de especialização, excetuando-se os cursos de aperfeiçoamento e outros; o segundo abrange cursos de mestrado e doutorado autorizados, reconhecidos e homologados pelo Ministério da Educação (MEC), mediante solicitação ao Conselho Nacional de Educação (CNE), de acordo com sua avaliação e recomendação pela CAPES (CAPES, 2018b). 
O sistema de avaliação dos cursos de PPGs é gerenciado pela CAPES, uma fundação do MEC que foi instituída por meio do Decreto $\mathrm{n}^{\mathrm{o}}$. 29.741, de 11 de julho de 1951 (na época, denominada Campanha Nacional de Aperfeiçoamento de Pessoal de Nível Superior), tendo como um dos seus objetivos a garantia do desenvolvimento de pessoal qualificado e em quantidade razoável para atender à demanda de empresas públicas ou privadas, devendo refletir no desenvolvimento social e econômico do Brasil (BRASIL, 1951).

Nesse contexto, a preocupação do Brasil pela qualidade do ensino superior tornou-se fundamental diante do panorama tecnológico, científico e de inovação mercadológica nacional e internacional, conforme relatam Maccari et al. (2014), os quais apontam as condições necessárias para a criação e a manutenção dos PPGs stricto sensu, com a chancela da CAPES. Isso se deve, também, ao fato de que a educação passou, ao longo dos anos, a integrar o processo de ampliação das perspectivas de se buscar a criação de valor agregado para o desenvolvimento de políticas públicas nas nações (HOUSE, 1992; VAN DAMME, 2000).

Nessa direção, no contexto brasileiro, isso tem sido materializado na importância do acompanhamento e da avaliação realizados pela CAPES. Em tal cenário, a manutenção da qualidade dos Programas de Pós-Graduação (PPGs) stricto sensu requer estratégias por parte dos gestores a fim de elevar e manter esses programas no patamar aceitável e de reconhecimento internacional nos campos de ensino, pesquisa e extensão (CAPES, 2018a).

Ressalta-se que o investimento realizado pelas entidades do governo brasileiro e pelo setor privado visam à formação de pessoal qualificado e ao desenvolvimento de pesquisas, para que ambos proporcionem retorno à sociedade brasileira e sejam considerados referência no âmbito internacional (OLIVEIRA et al., 2008).

Considera-se que o reconhecimento nacional e internacional dos PPGs é resultado do sistema de avaliação dos programas, efetuado pela CAPES (MACCARI et al., 2014). Esta avaliação é realizada a cada quatro anos, por intermédio da Plataforma Sucupira, com o objetivo de manter um padrão de qualidade junto aos programas avaliados e identificar possíveis desequilíbrios regionais, com a participação da comunidade acadêmica e científica (CAPES, 2018a).

A Plataforma Sucupira surgiu em 30 de maio de 2012, por meio de uma cooperação entre a CAPES e a Universidade Federal do Rio Grande do Norte (UFRN). Maccari et al. (2008) explicam que os cursos são avaliados e recomendados, levando-se em consideração cinco indicadores: proposta do programa, corpo docente, corpo discente, produção intelectual e inserção social.

Após findado o processo, a CAPES confere um conceito aos PPGs que varia de 1 a 7; entre os quais, 3 é a nota mínima para que o programa seja credenciado e faça parte do Sistema de Avaliação, e 7 a nota máxima, de excelência internacional, cujo ranqueamento define a distribuição dos recursos específicos do governo e atribui um selo de qualidade aos programas (MACCARI et al., 2014).

Ressalta-se que o processo se dá de duas formas distintas:

a) para a criação de cursos novos, por intermédio da apresentação das propostas enviadas pelas instituições de ensino superior e;

b) para a permanência dos cursos dos programas de pós-graduação, por intermédio da Plataforma Sucupira (CAPES, 2018b).

No tocante à permanência dos cursos no processo avaliativo, foco deste estudo, Martins e Maccari (2015) citam que o preenchimento das informações dos programas na plataforma é de responsabilidade dos coordenadores dos PPGs, que devem elaborar um planejamento estratégico que busque atender aos indicadores de avaliação dispostos no quadro 1, com pesos referentes à área de Engenharias IV, ao qual o PPGEAS pertence. 
Quadro 1 - Indicadores do Sistema de Avaliação da CAPES

\begin{tabular}{|c|c|c|}
\hline Indicador & Detalhamento & $\begin{array}{l}\text { Percentual }(\%) \\
\quad \text { na área } \\
\text { Engenharias IV }\end{array}$ \\
\hline $\begin{array}{l}\text { Proposta do } \\
\text { Programa }\end{array}$ & $\begin{array}{c}\text { Coerência e consistência da proposta; adequação e abrangência } \\
\text { das áreas de concentração e linhas de pesquisa à proposta do } \\
\text { programa; infraestrutura, cooperações e impactos regional, } \\
\text { nacional e internacional. }\end{array}$ & $\begin{array}{c}0 \\
\text { (Qualitativo) }\end{array}$ \\
\hline Corpo Docente & $\begin{array}{l}\text { Diversidade da formação, experiência e projeção nacional e } \\
\text { internacional; adequação e dedicação; distribuição da carga } \\
\text { letiva, regime de trabalho e dedicação; participação nas } \\
\text { atividades de ensino e pesquisa na graduação e pós-graduação. }\end{array}$ & 20 \\
\hline Corpo Discente & $\begin{array}{l}\text { Quantidade de Dissertações e Teses concluídas em relação ao } \\
\text { corpo docente permanente e ao quantitativo de discentes; relação } \\
\text { orientador/discente; qualidade de Dissertações e Teses; eficiência } \\
\text { na formação de mestres e doutores; tempo de formação. }\end{array}$ & 35 \\
\hline $\begin{array}{l}\text { Produção } \\
\text { Intelectual }\end{array}$ & $\begin{array}{l}\text { Publicações e respectivos Qualis de avaliação de periódicos, } \\
\text { relacionadas à distribuição do corpo docente. }\end{array}$ & 35 \\
\hline Inserção Social & $\begin{array}{l}\text { Inserção e impacto regional ou nacional do programa; integração } \\
\text { com outros programas; visibilidade dada pelo programa. }\end{array}$ & $\begin{array}{c}10 \\
\text { (Qualitativo) }\end{array}$ \\
\hline
\end{tabular}

Fonte: adaptado de CAPES (2017).

Maccari et al. (2008) já ressaltavam a relevância dos indicadores no desenvolvimento da pós-graduação no país, percebido pelo aumento qualitativo e quantitativo de cursos, tanto de mestrado quanto de doutorado. Assim, os indicadores representam os norteadores do sistema de avaliação da CAPES e que, de maneira direta, impactam no direcionamento das estratégias dos programas de pós-graduação para atendê-los (MACCARI et al., 2009; ALMEIDA, 2010).

Enfatiza-se, ainda, que os Comitês de Área da CAPES podem alterar os percentuais de cada indicador, apresentado no Documento de Área relacionado ao programa, cuja variação pode alcançar até o percentual de 5\% (MACCARI et al., 2009). Além disso, a CAPES estabelece um conjunto de diretrizes que se aplicam a todos os programas, a fim de realizar comparações entre as áreas de conhecimento abrangidas na avaliação, no intuito de identificar assimetrias e necessidades de adequações (MACCARI et al., 2014).

Vale destacar, ainda, que, embora a CAPES avalie, também, o detalhamento da Infraestrutura do programa, pois esta é necessária às atividades de ensino, pesquisa e extensão, a autonomia universitária (Artigo 207 da Constituição Brasileira) é considerada pela CAPES, visto que a instituição atua apenas como órgão de chancela de qualidade (FREITAS, 2011). Por fim, diante de um quadro crescente de criação de novos cursos de pós-graduação stricto sen$s u$, bem como da necessidade de gestão eficaz deles e dos que já estão em andamento no país, torna-se evidente, de forma análoga, a necessidade da correta manutenção e armazenamento de informações dos programas, assunto que será tratado na subseção seguinte.

\subsection{GESTÃO DA INFORMAÇÃO}

A informação é elemento fundamental para as organizações e, em função de seu crescente volume no ambiente organizacional, muitas vezes, é utilizado de forma ineficaz (MONTEZANO; SOUZA; BAETA, 2015). Os autores complementam ao dizerem que, para sanar esse problema, surgiu a gestão da informação.

Todavia, antes de tratar da gestão da informação, faz-se necessário o entendimento do significado de informação que, conforme Le 
Coadic (1996, p. 5), “é o conhecimento inscrito (gravado) sob a forma de escrita (impressa ou numérica), oral ou audiovisual" e possui como objetivo a compreensão dos seres, por meio do conhecimento, cujo meio é a estrutura de suporte para que isso ocorra.

Para Rezende (2016), a informação pode ser interpretada como uma entidade cujo valor significativo atribuído apresenta um sentido lógico e concreto, além de se apresentar no formato de documentos, programas ou arquivos. Vale destacar que a informação se associa a diversos campos da ciência.

Buckland (1999) diz que o fenômeno está presente nas mais diversas áreas de concentração (computação, matemática, linguística, etnografia, economia, direito); nas especializações (sistemas geográficos de informação, conjunto de dados sócio econômicos, websites); em contextos específicos (universidades, restaurantes, livrarias, clínicas médicas) e em situações variadas de ideologia (economia, política, culturas). Nesse sentido, o autor considera o cenário da informação uma situação complexa, visto que o conhecimento gerado por ela é significante em todos os contextos.

Ao direcionar a informação para o contexto organizacional, Araújo (2014) afirma que se trata de um importante recurso, mas que, no entanto, pode constituir um problema quando são encontradas dificuldades em seu volume (armazenamento), alcance (universo amplo) e circulação (chegada nos setores de interesse).

Ainda com relação ao entendimento da importância da informação, Pitassi e Moreno Júnior (2009) dizem ser essa uma das principais responsabilidades do gestor, em tempos contemporâneos, uma vez que a transformação de dados em informação é ação que alicerça a integração e a qualidade do conhecimento organizacional.

Completam tal posicionamento, Reginato e Gracioli (2012), ao dizerem ser importante dimensioná-la, principalmente, porque seu gerenciamento eficaz permite o desenvolvimento de organizações tornando-as competitivas. Vale destacar que, anteriormente, Moraes e Fadel (2009) consideraram que as informações, cujos significados representam elementos fundamentais ao desempenho da organização, distinguem-se em quatro tipos:

a) científica: proveniente da pesquisa e suas resultantes;

b) tecnológica: resultante da produção ou prestação de serviços e desenvolvimento no mercado;

c) estratégica: oriunda das tendências do mercado, contexto econômico, organizações concorrentes e expansão do ambiente operacional; e

d) de negócios: derivada de processo decisório e gerenciamento, finanças, estatísticas, legislação e mercado.

Diante do exposto, é possível compreender que as informações têm seu valor na tomada de decisões dos gestores (MORAES; FADEL, 2009) e, ainda, que elas precisam ser rápidas, exatas e com qualidade, pois se tornaram recursos essenciais na produtividade das organizações, cuja gestão envolve a redução de excessos, a otimização da circulação e a precisão dos seus dados (ARAÚJO, 2014).

A gestão da informação, portanto, é a ação que garante a efetividade dos serviços, para o alcance dos objetivos da organização, sejam eles em escala micro ou macro (COSTA, 2017). Todavia, é preciso que profissionais com competência para tal ação assumam papéis de gerenciamento, como o secretário executivo, conforme teorizado na próxima seção.

\subsection{O PROFISSIONAL DE SECRETARIADO E A ASSESSORIA EXECUTIVA}

A evolução da profissão secretarial tem aderência com a gestão de informações, por causa de o trabalho secretarial ser vinculado à guarda, à transferência e ao controle de diversos tipos de informação, em meio à crescente incorporação de novas responsabilidades (GARFIELD, 1986; GILLES; VALLES; PERRYMAN, 1996). No Brasil a trajetória dessa profissão é marcada por diversos acontecimentos; entre eles, destacam-se a legislação, por 
meio da Lei 7.377, de 30 de setembro de 1985, que dispõe sobre o exercício da profissão de secretário, posteriormente alterada pela Lei n. 9261, de 11 de janeiro de 1996.

Outros dois marcos legais relevantes são a inclusão da profissão na Classificação Brasileira de Ocupações (CBO), instituída pela Portaria do Ministério do Trabalho $n^{\circ} .397$, de 9 de outubro de 2002, bem como pela publicação da Resolução no 3/2005 do Ministério da Educação (MEC), que trata das diretrizes curriculares para os cursos de graduação em secretariado executivo (BRASIL, 1985, 1996, 2002, 2005).

Vale salientar que, entre o rol de competências do profissional de secretariado executivo, destacadas na Resolução $n^{0} 3 / 2005$, a que se alinha ao foco deste estudo está a "gestão e assessoria administrativa com base em objetivos e metas departamentais e empresariais." (BRASIL, 2005). Dessa forma, tem-se que a assessoria passa a ser um meio pelo qual o secretário é capaz de demonstrar suas habilidades em todas as esferas administrativas (COSTA; VIANA, 2016).

Ressalta-se que a evolução das competências secretariais ocorreu, entre outros fatores, por meio da necessidade das organizações em haver em seus quadros funcionais, profissionais capazes de gerir e estruturar informações, no sentido de eles contribuírem, por exemplo, com a viabilização dos negócios (DAVENPORT, 2013). A aproximação da profissão secretarial com o assessoramento é retratada por Nonato Júnior (2009), que definiu quatro eixos de assessoria, ilustrados no quadro 2.
Importante destacar, ainda, que a competência de assessoramento é elemento disposto nos marcos legais da profissão e que o profissional de secretariado ganhou destaque e passou a conquistar seu próprio espaço nas organizações por meio do alcance de melhores posicionamentos. Isso é fruto do reconhecimento e da capacitação adquirida na formação acadêmica (MARTINS et al., 2010).

Tal dado pôde revelar suas competências por intermédio de funções como a assessoria, que antes eram atribuições apenas do alto escalão de gestores (MAÇANEIRO; CATCZU, KORCHAQUE, 2012). Na mesma linha teórica, Costa e Viana (2016, p. 35) dizem que o profissional assessor é aquele "[...] imbricado com o saber, tendo extenso conhecimento no âmbito organizacional com capacidade de orientação e aconselhamento [...]."

Além disso, outras competências contemporâneas diversificadas podem ser atribuídas a esse profissional; entre elas, a de gestor da informação em diversos contextos, como o estratégico organizacional, por exemplo, e/ou alinhada a outras competências, como a de gestão de conflitos, de processos, voltada ao empreendedorismo, à liderança e ao trabalho em equipe, entre outras (MOREIRA et al., 2016; RODRIGUES; LAVARDA; MARTINS, 2017).

Para Montezano, Souza e Baeta (2015), a gestão da informação é fruto da necessidade das organizações em buscar melhorias no gerenciamento dos recursos informacionais para elevar a eficiência da gestão estratégica orga-

Quadro 2 - Eixos do assessoramento no campo secretarial

\begin{tabular}{|c|c|c|}
\hline $\begin{array}{c}\text { EIXO } \\
\text { Assessoramento }\end{array}$ & $\begin{array}{c}\text { ASSESSORIA } \\
\text { Operacional }\end{array}$ & $\begin{array}{l}\text { DESCRIÇÃO } \\
\text { Técnica e tática, ligadas às rotinas secretariais, às técnicas e } \\
\text { tecnologias. }\end{array}$ \\
\hline Assessorexe & Executiva & $\begin{array}{l}\text { Gestor do conhecimento; interligando o fazer e o saber do } \\
\text { profissional nas atividades gerenciais. }\end{array}$ \\
\hline Assessorística & Intelectual & $\begin{array}{l}\text { Assessor de pesquisa, de produção e análise de dados, elaboração } \\
\text { textual e discursiva e ainda na assessoria científica. }\end{array}$ \\
\hline Assessorab & Aberta & $\begin{array}{l}\text { Atuação no desenvolvimento de práticas secretariais para além } \\
\text { do ambiente organizacional; relações entre as assessorias e outras } \\
\text { áreas do conhecimento. }\end{array}$ \\
\hline
\end{tabular}

Fonte: elaborado pelos autores com base em Nonato Júnior (2009). 
nizacional, que se encontra ineficiente. Os autores citam ainda que as informações representam a base para que se possa tomar decisões estratégicas das organizações, as quais envolvem tanto o ambiente interno quanto o externo.

Assim, constata-se, ainda, que o profissional de secretariado é um gestor da informação não só pelo teorizado por Moreira et al. (2016), mas porque os eixos de assessoria de Nonato Júnior (2009) trazem indícios de que é necessário saber gerir informações para assessorar. Em Programas de Pós-Graduação (PPGs) brasileiros, por exemplo, Soares e Pauly (2018), em um estudo acerca da atuação dos secretários na gestão dos PPGs stricto sensu do sul do Brasil, observaram a atuação dos secretários na gestão da maior parte das informações inseridas na Plataforma Sucupira e que são destinadas à avaliação dos programas pela CAPES.

Os autores (SOARES; PAULY, 2018, p. 23) ressaltaram, ainda, que "as secretarias dos PPGs inserem os dados administrativos e pedagógicos sob sua responsabilidade pelo Portal do Coordenador, tornando invisível o trabalho e a respectiva responsabilidade dos profissionais de Secretariado", o que demonstra a relevância da atuação do secretário como gestor da informação do PPG para posterior avaliação da CAPES.

Sob tal lógica, o secretário executivo tem, então, competência para auxiliar não só os coordenadores de cursos de PPG, mas a coordenação em si, visto que o cargo do primeiro é temporário, e o de secretário, permanente. Em continuidade, na próxima seção, abordam-se os procedimentos metodológicos utilizados na condução deste trabalho e, na sequência, os dados e resultados encontrados.

\section{PROCEDIMENTOS METODOLÓGICOS}

Nesta pesquisa, utilizou-se a abordagem qualitativa, que permitiu a análise dos dados obtidos sem quantificá-los, para adentrar na análise de comportamento do indivíduo e para compreender o fenômeno de interesse como um processo permeado pela ação de agentes que atuam em um determinado ambiente organizacional (TRIVIÑOS, 2010).

Trata-se, quanto aos fins, de uma investigação de natureza descritiva acerca do objetivo proposto (VERGARA, 2007), a qual trata de descrever " [...] características de determinada população ou fenômeno ou o estabelecimento de relações entre variáveis." (SILVA; MENEZES, 2005, p. 15).

Descreveu-se o ambiente de estudo, bem como os processos e as rotinas da secretaria do PPGEAS, que se alinhavam à gestão da informação, para relacioná-los às exigências do sistema de avaliação pela CAPES e, assim, verificar como o profissional de Secretariado Executivo, por meio de assessoria, pode contribuir para o atendimento das exigências do sistema de avaliação da CAPES, no ambiente.

Quanto aos meios utilizados para a investigação, optou-se pela pesquisa de campo. Esta é uma "investigação empírica realizada no local onde ocorre ou ocorreu um fenômeno ou que dispõe de elementos para explicá-lo" (VERGARA, 2007, p. 47). O ambiente pesquisado foi o Programa de Pós-Graduação em Engenharia de Automação e Sistemas (PPGEAS) que, em função da promoção ao conceito 6 da avaliação quadrienal CAPES, esta realizada em 2017 e divulgada no mesmo ano, demonstrou desempenho satisfatório perante os critérios avaliativos (CAPES, 2017).

Por esse motivo, foi compreendido neste estudo como um programa com representatividade quanto à gestão de informações na Plataforma Sucupira. Tal fato foi considerado por meio da lente teórica da gestão da informação, em alinhamento com o que preconiza a gestão secretarial voltada para a competência de assessoria executiva.

Em relação aos procedimentos técnicos de coleta de dados, os secundários foram levantados por meio das pesquisas bibliográfica e documental. Para a primeira, contemplaram-se materiais produzidos com fins científicos, os quais foram selecionados por meio da leitura e seleção de textos relacionados ao tema de estudo, com a finalidade de construção do 
referencial teórico (ROESCH, 2009).

A relação dos materiais de interesse foi estabelecida por meio de buscas por palavras-chave, como: Secretário Executivo, Assessoria, Assessoria Executiva e Avaliação CAPES, juntas ou isoladas. Estas foram pesquisadas em fontes bibliográficas de acesso público como artigos científicos, investigados nas bases de dados Scielo, Google Acadêmico, Researchgate e revistas científicas da área secretarial e administração, nacionais e internacionais.

A segunda foi subsidiada por materiais produzidos com fins organizacionais/gerenciais, que não sofreram tratamento prévio, trazendo dados brutos que devem ser sintetizados para fins de pesquisa (MARCONI; LAKATOS, 2008). Foram obtidas informações recorrendo-se a leis, relatórios e dados do sítio da CAPES, a fim de identificar os parâmetros avaliativos de seu Sistema de Avaliação e que norteiam o objetivo geral proposto neste trabalho.

O recorte temporal delineado, tanto para o levantamento bibliográfico quanto documental, compreendeu o período entre 2013 e 2017, pois pretendeu-se investigar informações do último quinquênio. Foram utilizadas, ainda, obras de autores clássicos que já tratavam do tema antes desse período, a fim de reforçar o arcabouço teórico, o que possibilitou, também, a identificação das dimensões analíticas do estudo, apresentadas no quadro 3.

Para a coleta de dados primários, optou-se pela técnica de observação participante, por meio da qual um dos investigadores, que é secretário executivo, realizou a observação na secretaria do PPGEAS para verificar a possibilidade de atuação do profissional de Secretariado com base nas competências secretarias relacionadas à gestão da informação e inerentes ao sistema de avaliação da CAPES.

Desse modo, por meio da observação participante, foi possível atuar no acompanhamento das atividades administrativas, tanto do coordenador do programa quanto do profissional designado para essa secretaria. E, para isso, o trabalho de registro das observações foi documentado em diário de campo. Assim, foi possível observar o papel do sujeito analisado, momento em que a convivência do investigador com o investigado proporcionou condições favoráveis à compreensão dos processos desenvolvidos no ambiente de pesquisa (MARTINS, 1996).

Os elementos de interesse do processo de observação constam descritos no quadro 3 . Ademais, por intermédio da observação participante, foi possível ter acesso às informações do programa, as quais se encontravam disponíveis em documentos da secretaria do PPGEAS, no site do programa e na Plataforma Sucupira. Para subsidiar a coleta e o tratamento dos dados, foram estabelecidas dimensões analíticas, conforme o quadro 3 , por meio do referencial teórico. Isso possibilitou a tomada de decisões em relação às evidências do estudo (GIL, 2002).

Ademais, destaca-se que, como técnica de análise de dados, utilizou-se de um conjunto de técnicas de análise das comunicações que utilizam procedimentos sistemáticos e objetivos de descrição do conteúdo das mensagens, para buscar o entendimento da mensagem do emissor ou do meio em questão (BARDIN, 2011), os quais são operacionalizados por categorias de análise constantes do quadro 3. 
Quadro 3 - Coerência interna da pesquisa.

\begin{tabular}{|c|c|c|c|}
\hline \multicolumn{4}{|c|}{$\begin{array}{l}\text { Objetivo Geral: verificar como o assessoramento secretarial, associado à gestão da informação, pode } \\
\text { colaborar no processo de avaliação da CAPES, no Programa de Pós-Graduação em Engenharia de } \\
\text { Automação e Sistemas (PPGEAS) }\end{array}$} \\
\hline $\begin{array}{l}\text { Indicadores do } \\
\text { Sistema de Avaliação } \\
\text { da Capes }\end{array}$ & $\begin{array}{l}\text { Dimensões Teórico- } \\
\text { Analíticas } \\
\text { (DTA) }\end{array}$ & $\begin{array}{c}\text { Categoria Analítica } \\
\text { (CA) }\end{array}$ & $\begin{array}{c}\text { Técnica quanto aos } \\
\text { dados }\end{array}$ \\
\hline $\begin{array}{l}1 \text { - Proposta do } \\
\text { Programa } \\
2 \text { - Corpo docente; } \\
3 \text { - Corpo discente; } \\
4 \text { - Inserção social. }\end{array}$ & $\begin{array}{l}\text { DTA1: Tipos de informações } \\
\text { no processo de gestão da } \\
\text { Informação: } \\
\text { a) científica; } \\
\text { b) tecnológica; } \\
\text { c) estratégica; } \\
\text { d) de negócios. } \\
\text { (MORAES; FADEL, 2009) } \\
\text { DTA2: Eixos da Assessoria } \\
\text { Executiva secretarial: } \\
\text { a) Assessoramento; } \\
\text { b) Assessorexe; } \\
\text { c) Assessorística; } \\
\text { d) Assessorab. } \\
\text { (NONATO JÚNIOR, 2009) }\end{array}$ & $\begin{array}{l}\text { CA1: Atividades que } \\
\text { envolvem assessoria } \\
\text { para a redução de } \\
\text { excessos e a melhora na } \\
\text { produção, circulação e } \\
\text { precisão da informação, } \\
\text { considerado o tipo de } \\
\text { informação relacionado } \\
\text { ao Sistema de Avaliação } \\
\text { da Capes e com base } \\
\text { nos tipos e assessoria } \\
\text { secretarial. }\end{array}$ & $\begin{array}{l}\text { Bibliográfica } \\
\text { e documental } \\
\text { (secundários) } \\
\text { e Observação } \\
\text { participante } \\
\text { (primários) }\end{array}$ \\
\hline
\end{tabular}

Fonte: elaborado pelos autores (2018).

Por meio dos elementos dispostos no quadro 3, pretendeu-se alcançar o objetivo geral delineado nesta pesquisa, por intermédio das dimensões teóricas e categorias analíticas principais (CA1 e CA2) ora citadas. A seguir, passa-se para os resultados da pesquisa.

\section{RESULTADOS E DISCUSSÕES}

\subsection{CARACTERIZAÇÃO DO AMBIENTE DO ESTUDO}

Antes da análise efetiva dos dados, considera-se importante uma breve contextualização do ambiente em que este estudo foi desenvolvido. Assim, tem-se que a Universidade Federal de Santa Catarina (UFSC), local onde foi realizada esta pesquisa, é uma Instituição de Ensino Superior fundada em 1960 e credenciada pelo Ministério da Educação (MEC), conforme Lei Federal ${ }^{\circ}$ 3.849, de 18 de dezembro 1960 (BRASIL, 1960).

Na UFSC, são desenvolvidos diversos cursos de graduação e pós-graduação. Desde 1969, quando surgiram os primeiros PPGs Engenharia de Produção e Engenharia Mecânica - na UFSC, outros PPGs foram criados nesta Instituição nos anos subsequentes, o que levou ao número atual de 117 PPG ofertados pela Instituição (UFSC, 2018a).

Entre os PPGs existentes e distribuídos nos Centros de Ensino da UFSC, encontra-se o Programa de Pós-Graduação em Engenharia de Automação e Sistemas (PPGEAS), que teve sua origem em 2007 no Campus de Florianópolis e está vinculado ao Departamento de Automação e Sistemas (DAS) e ao Centro Tecnológico (CTC) da UFSC. O PPGEAS, a partir de 2018, foi avaliado como conceito 6 pela CAPES e passou a compor o Programa de Excelência Acadêmica (PROEX) e compõe a área de avaliação Engenharias IV (UFSC, 2018b).

Em relação à composição de seu quadro docente, o PPGEAS conta com 27 professores; entre eles, 21 credenciados como permanentes e seis como colaboradores, os quais desenvolvem quatro linhas de pesquisa: Controle, Automação e Sistemas Mecatrônicos; Sistemas 
Computacionais e Automação; Controle, Otimização e Instrumentação para a Indústria de Petróleo e Gás (UFSC, 2018b). O processo de credenciamento de professores no programa ocorre a cada quatro anos, de acordo com resolução específica do PPGEAS, em conformidade com a Resolução Normativa N. 95/CUn/2017 e homologado pela Câmara de Pós-Graduação da Instituição (UFSC, 2017).

No que diz respeito à gestão, o PPGEAS é composto por uma Coordenação que atua tanto nos assuntos didáticos quanto administrativos, constituída pelo coordenador e subcoordenador, eleitos entre os docentes credenciados como permanentes, conforme previsto no Regimento Interno do programa, cujo mandato é de, no mínimo, dois anos, permitida uma reeleição por mais dois anos (UFSC, 2017). Para compor a estrutura administrativa, o programa conta com uma secretaria e órgãos complementares (colegiados e comissões). Esses últimos, compostos por membros do corpo docente e discente do PPGEAS, designados pela coordenação para desempenhar funções auxiliares à coordenação (UFSC, 2018b).

\subsection{A ASSESSORIA SECRETARIAL NO CONTEXTO DO SISTEMA DE AVALIAÇÃO DA CAPES}

Em continuidade, passa-se a discussão das evidências sobre as atividades ocorridas na secretaria, local onde a observação participante ocorreu, neste caso especificamente, sobre aquelas que envolvem a avaliação da CAPES e a inserção de informações na plataforma Sucupira, as quais se relacionam às ações cotidianas nos PPGs. Para o desenvolvimento deste estudo, foram explorados elementos que se alinhavam à gestão de informações, vinculados ao assessoramento secretarial, a serem inseridas naquela plataforma, por meio dos indicadores de avaliação da CAPES.

Segundo Maccari et al. (2008), os indicadores representam elementos que compõem os critérios avaliativos dos programas, com o intuito de estabelecer padrões de qualidade e alavancar a pós-graduação do país. Ressalta-se que os dados sobre o assessoramento foram coletados por intermédio da pesquisa documental e durante a observação participante. No quadro 4, apresenta-se a síntese do ora proposto.

Quadro 4 - Síntese da associação entre gestão da informação para avaliação da CAPES e assessoramento secretarial no PPGEAS

\begin{tabular}{|c|c|c|}
\hline $\begin{array}{l}\text { Indicador do } \\
\text { Sistema de } \\
\text { Avaliação }\end{array}$ & $\begin{array}{l}\text { Dimensão Teórica } \\
\text { (DT) }\end{array}$ & Categoria Analítica (CA): atividades que envolvem assessoria \\
\hline $\begin{array}{c}\text { Proposta do } \\
\text { Programa }\end{array}$ & $\begin{array}{l}\text { DT2: } \\
\text { Assessoramento, } \\
\text { Assessorexe e } \\
\text { Assessorística }\end{array}$ & $\begin{array}{l}\text { - Registro e manutenção das linhas e projetos de pesquisa; } \\
\text { - Assessoramento e registro dos convênios institucionais } \\
\text { (nacionais e internacionais) e cotutela (dupla titulação); } \\
\text { - Assessoramento nos processos seletivos de discentes (brasileiros } \\
\text { e estrangeiros), operacionalização, análise e divulgação } \\
\text { dos resultados e anotação dos novos alunos no CAPG e na } \\
\text { Plataforma Sucupira. }\end{array}$ \\
\hline Corpo Docente & $\begin{array}{l}\text { DT1: Científica, } \\
\text { Tecnológica, } \\
\text { Estratégica, de } \\
\text { negócios }\end{array}$ & $\begin{array}{l}\text { - Registros do Estágio Pós-Doutoral e participação dos docentes } \\
\text { em cursos de instituições estrangeiras; } \\
\text { - Lançamento da distribuição da carga-horária e das disciplinas } \\
\text { ministradas por semestre; } \\
\text { - Assessoramento e anotação da participação dos docentes em } \\
\text { outros programas, projetos e divulgação de pesquisa científica } \\
\text { por intermédio do auxílio a eventos, processos de pagamento } \\
\text { de inscrição, compra de passagens aéreas, encaminhamento de } \\
\text { pedidos de reembolso. }\end{array}$ \\
\hline
\end{tabular}




\begin{tabular}{|c|c|c|}
\hline Corpo Discente & $\begin{array}{l}\text { DT2: } \\
\text { Assessoramento, } \\
\text { Assessorexe e } \\
\text { Assessorística }\end{array}$ & $\begin{array}{l}\text { - Controle de documentos para processos de defesa (Qualificação } \\
\text { e Defesa de Dissertação), organização das bancas (portarias, } \\
\text { atas), aquisição de passagens aéreas e lançamento de diárias } \\
\text { para membros externos (relatório de viagem), alocação de } \\
\text { espaço físico, prestação de contas de passagens e diárias e } \\
\text { registro das defesas no Controle Acadêmico de Pós-Graduação } \\
\text { (CAPG) e na Plataforma Sucupira; } \\
\text { - Gerenciamento de bolsas no Sistema de Acompanhamento de } \\
\text { Concessões (SAC) da CAPES na Plataforma Sucupira, emissão } \\
\text { de declarações e gestão de lista de espera; } \\
\text { - Controle da quantidade de créditos cursados, conceitos e tempo } \\
\text { para finalização do curso. }\end{array}$ \\
\hline $\begin{array}{l}\text { Produção } \\
\text { Intelectual }\end{array}$ & $\begin{array}{l}\text { DT1: Científica } \\
\text { DT2: } \\
\text { assessorística, } \\
\text { assessoramento }\end{array}$ & $\begin{array}{l}\text { - Acompanhamento da produção científica de docentes em } \\
\text { conjunto com os discentes, respectivos Qualis e verificação de } \\
\text { Currículo Lattes atualizado. }\end{array}$ \\
\hline Inserção Social & $\begin{array}{l}\text { DT1: Tecnológica, } \\
\text { Estratégica e de } \\
\text { negócios } \\
\text { DT2: assessorab }\end{array}$ & $\begin{array}{l}\text { - Assessoramento na realização de palestras de docentes do } \\
\text { programa de professores convidados (brasileiros e estrangeiros) } \\
\text { e registro correspondente; } \\
\text { - Suporte em convênios dos programas com outras IES nacionais } \\
\text { ou internacionais e na participação de docentes em Estágio Pós- } \\
\text { Doutoral ou em cursos de instituições estrangeiras e respectivos } \\
\text { registros. }\end{array}$ \\
\hline
\end{tabular}

Fonte: elaborado pelos autores (2018).

O quadro 4 apresenta uma síntese dos resultados do estudo, com base no que preconiza a literatura. Isso significa dizer, para fins de avaliação, naquilo que determina a CAPES, que são necessárias séries de informações sobre o Programa, as quais, pela quantidade de atividades expostas na coluna três, precisam ser geridas de forma efetiva. Assim, por meio do quadro 4, foi possível observar que a secretaria do PPGEAS atua na gestão de diversas informações do programa e que envolve a totalidade dos indicadores da CAPES.

Assim, em relação aos três primeiros indicadores analisados, quais são:

a) "Proposta do Programa" (desde o ingresso de novos alunos até as relações nacionais e internacionais do programa com outras instituições por meio dos convênios e acordos de cotutela);

b) "Corpo Docente" (distribuição de carga horária em atividades de ensino, pesquisa e extensão e o estágio pós-doutoral e apoio financeiro para a publicação das produções científicas em revistas científicas nacionais e internacionais) e;

c) "Corpo Discente" (registros e emissões de documentos por meio do sistema acadêmico de pós-graduação - CAPG, controle de créditos e gerenciamento de plataformas das agências de fomento do governo federal $\mathrm{CNPq}$ e CAPES), é possível verificar que eles impactam no direcionamento de ações estratégicas do coordenador quanto ao alcance dos resultados esperados pelo programa, principalmente, por se tratar de um programa PROEX.

Por meio desses três indicadores, verificou-se a possibilidade de atuação do secretário executivo no que tange às assessorias elencadas por Nonato Junior (2009), como operacional (assessoramento), ligadas às técnicas aplicadas às rotinas da secretaria, executiva (assessorexe) 
na interlocução entre o saber fazer e o gerenciamento preciso do sistema e intelectual (assessorística), quando na análise das informações e elaboração textual, principalmente, no auxílio da elaboração da "Proposta do Programa".

Além disso, observou-se que o profissional de Secretariado é capaz de gerir as informações do programa investigado de modo a garantir a celeridade e diminuir excessos de informação, garantindo a precisão das informações do programa registradas na Plataforma Sucupira que serão, posteriormente, avaliadas pela CAPES. Essa atuação do profissional de Secretariado vai ao encontro do investigado por Soares e Pauly (2018), quando verificada a atuação do secretário na gestão das informações e seu reflexo nas ações estratégicas dos programas analisados, principalmente, relacionadas à "Proposta do Programa".

A respeito da "Produção Intelectual", a secretaria realiza a coleta e o registro, na mesma plataforma, das produções que envolvem docentes em conjunto com discentes do programa, cuja relevância impacta em 35\% nessa avaliação. As atividades observadas com relação a esse indicador também demonstram a possibilidade de atuação do Secretário Executivo quanto às assessorias intelectual (assessorística), por meio da investigação de informações na plataforma Lattes.

Para inserção de informações na plataforma Lattes, é necessário, na maioria das vezes, a investigação e complementação de informações dessas produções para registro na plataforma; e operacional (assessoramento), relacionado às técnicas e táticas rotineiras necessárias para obtenção dessas informações. Ainda, o secretário pode realizar o registro das informações precisas, sem excessos, além garantir a circulação dessas informações na Plataforma Sucupira.

Por fim, o indicador denominado "Inserção Social", que representa o menor percentual na avaliação (10\%), envolve a atuação dos docentes do programa em eventos nacionais e internacionais, ou por intermédio da recepção de docentes externos ao programa, observou-se novamente a capacidade do secretário executivo na atuação por meio da assessoria aberta (assessorab) - projetos interdisciplinares que extrapolam os limites institucionais - e que promovem a comunicação entre o programa e a comunidade científica, embora esse indicador represente um percentual baixo (10\%) na avaliação.

Em síntese, foi possível verificar que o profissional de secretariado executivo pode contribuir com o processo de avaliação do sistema CAPES, no PPGEAS, quando utiliza de suas competências para a assessoria, conforme os eixos definidos por Nonato Júnior (2009). Identificou-se que há uma diversidade de informações demandadas pelo sistema e que o coordenador do Programa, por haver outras atividades e, ainda, por não ser um ator fixo no ambiente, precisa contar com um profissional habilitado que conheça todo o processo em continuidade. Em outras palavras, que esteja presente na secretaria de forma ininterrupta, a fim de que as informações sejam gerenciadas de forma efetiva, sem "perda" do conhecimento, fato que pode ocorrer pela alternância do sujeito coordenador.

Ainda sobre o assessoramento secretarial, é notável a quantidade de ações a serem realizadas na secretaria do PPGEAS e, por conseguinte, as informações a serem gerenciadas. Vale ressaltar que a manutenção da Plataforma Sucupira, a priori, é de responsabilidade do coordenador do programa; no entanto, a demanda de atividades administrativas (na coordenação) somadas às acadêmicas, visto que um professor, ao assumir função na administração acadêmica, não deixa de exercer funções em sala de aula. Mesmo assim, é notável que o gerenciamento da Plataforma no PPGEAS passou a compor as atividades de rotina da secretaria, que assessora o coordenador na gestão das informações necessárias para o processo de avaliação.

É importante destacar também, neste contexto específico, que considerado o assessoramento secretarial, todos os eixos de assessoria definidos por Nonato Júnior (2009) estão incorporados:

a) operacional: visto que a gestão da in- 
formação está associada à rotina secretarial do PPGEAS;

b) executiva: já que, se há informação, há conhecimento e, neste caso, é preciso administrá-lo para gerenciamento do sistema;

c) intelectual: porque que há produção e análise de dados para inserção no sistema e;

d) aberta: quando o assessoramento ocorre, inclusive, em projetos interdisciplinares e em relações de cooperação científica com instituições nacionais e internacionais.

Por último, é importante dizer que se apresentou, neste estudo, a figura do profissional de secretariado executivo, o qual desenvolve, durante sua formação competências, definidas por regulamentação, para o assessoramento e para a gestão da informação, conforme posto introdutoriamente e, ainda, que esse profissional encontra na legislação da Instituição (UFSC, 2005) sustentação para atuar nessas funções. É essencial dizer ainda, que a assessoria secretarial não está presente em todos os PPGs da UFSC, pelo contrário, são poucas as coordenadorias que contam com a atuação desse profissional e que este estudo ressalta a competência secretarial, sem, no entanto, desconsiderar as demais categorias, que realizam trabalho análogo.

\section{CONSIDERAÇÕES FINAIS}

A assessoria, por suas características, é uma competência secretarial, que permite ao profissional atuar nas mais variadas áreas, neste trabalho, no campo da gestão da informação. Ao final da pesquisa, pôde-se constatar que o objetivo proposto, como o assessoramento secretarial, associado à gestão da informação, pode colaborar no processo de avaliação da CAPES, no Programa de Pós-Graduação em Engenharia de Automação e Sistemas (PPGEAS), foi atingido, quando se confirmou a possibilidade do gerenciamento de informações no processo de avaliação da CAPES, no ambiente em estudo, por meio do assessoramento do profissional secretário.

Em outras palavras e, conforme os resultados obtidos, todas as formas de assessoramento secretarial, dispostas por Nonato Júnior (2009), abrangem alguma ação relacionada ao processo de Avaliação da CAPES, principalmente, naquilo que concerne à gestão das informações necessárias para "alimentação" do sistema, bem como a inserção dos dados propriamente dita.

Nesse sentido, acredita-se que a atuação de um profissional fixo no ambiente de estudo e, somado a isso, tenha competências de formação que sustentam sua atuação é essencial, principalmente, em períodos de transição da equipe da coordenação do programa, momento que se supõe ser crítico no que se refere à conservação das informações. Diante dessa conjuntura, foi possível observar a importância da participação de um profissional capacitado, responsável pela manutenção das informações do programa relacionadas ao Sistema de Avaliação da CAPES.

Observa-se que este estudo tratou de ações que ocorreram na secretaria de um programa de pós-graduação em específico, o PPGEAS. Em tal local, foi possível verificar a viabilidade de atuação do profissional de secretariado em ações de assessoria e em circunstâncias específicas: em atividades que envolvem a avaliação do programa; no período compreendido com base em informações do último quinquênio, ou seja, entre 2013 e 2017; conforme os procedimentos metodológicos adotados; durante a transição do conceito atribuído pelo Sistema de Avaliação da CAPES, que passou a avaliar o PPGEAS de 5 para 6 e, portanto, conferiu a categoria de PROEX ao programa em análise.

Nesse sentido, embora os resultados apresentados não possam nortear ações de outros programas, entende-se que esta pesquisa pode auxiliar na estruturação de planos de gestão de informações, assim como na assessoria de outros programas com finalidades em comum, em relação ao alcance de conceitos satis- 
fatórios conferidos pela CAPES, tendo em vista o protocolo de análise adotado. Para estudos futuros, propõe-se o aprofundamento do tema da assessoria secretarial e seus impactos no desempenho de outros programas de pós-graduação, perante o quadriênio seguinte: 2017-2020, para atender aos indicadores do Sistema de Avaliação da CAPES.

\section{REFERÊNCIAS}

ALMEIDA, M. H. A Pós-Graduação no Brasil: onde está e para onde poderia ir. 2010. Disponível em: https://www.gov.br/capes/pt-br/ centrais-de-conteudo/pnpg-miolo-v2-pdf/view. Acesso em: 3 dez. 2020.

ARAÚJO, C. A. A. Fundamentos da Ciência da Informação: correntes teóricas e o conceito de informação. Revista Perspectivas em Gestão \& Conhecimento, João Pessoa, v. 4, n. 1, p. 57-79, jan./jun. 2014. Disponível em: http:// periodicos.ufpb.br/ojs/index.php/pgc/article/ view/19120. Acesso em: 25 jan. 2018.

BARDIN, L. Análise de conteúdo. São Paulo: Edições 70, 2011.

BRASIL. Decreto N. 29.741, de 11 de julho de 1951. Institui uma Comissão para promover a Campanha Nacional de Aperfeiçoamento de Pessoal de Nível Superior. 1951. Disponível em: http:// www2.camara.leg.br/legin/fed/decret/1950-1959/ decreto-29741-11-julho-1951-336144-norma-pe. html. Acesso em: 13 fev. 2018.

BRASIL. Lei $\mathbf{n}^{\mathbf{0}}$ 3.849, de 18 de dezembro de 1960. Federaliza a Universidade do Rio Grande do Norte, cria a Universidade de Santa Catarina e dá outras providências. 1960. Disponível em: http://www6.senado.gov.br/legislacao/ ListaTextoIntegral.action?id=86921. Acesso em: 13 jan. 2018.

BRASIL. Lei n. 7.377, de 30 de setembro de 1985. Dispõe sobre o Exercício da Profissão de Secretário. Brasília, DF: Presidência da Repú- blica, 1985. Disponível em: http:/www.planalto.gov.br/ccivil_03/leis/17377.htm. Acesso em: 25 jan. 2018.

BRASIL. Lei n. 9261, de 11 de janeiro de 1996. Altera a redação dos incisos I e II do art. $2^{\circ}$, o caput do art. $3^{\circ}$, o inciso VI do art. $4^{\circ}$ e o parágrafo único do art. $6^{\circ}$ da Lei $n^{\circ} 7.377$, de 30 de setembro de 1985. Brasília, DF: Presidência da República, 1996. Disponível em: http:// www.planalto.gov.br/ccivil_03/Leis/L9261. htm. Acesso em: 23 jan. 2018.

BRASIL. Portaria no 397 , de 09 de outubro de 2002. Aprova a Classificação Brasileira de Ocupações - CBO/2002, para uso em todo território nacional e autoriza a sua publicação. 2002. Disponível em: http://www.portaldoservidor.sc.gov.br/ckfinder/userfiles/arquivos/ Legislacao\%20Correlata/Portarias/2002_-portaria_n\%C2\%BA_397\%2C_de_09_de_outubro_de_2002.pdf. Acesso em: 1 fev. $\overline{2} 01 \overline{8}$.

BRASIL. Resolução no 3 , de 23 de junho de 2005. Institui as Diretrizes Curriculares Nacionais para o curso de graduação em Secretariado Executivo e dá outras providências. 2005. Disponível em: http://portal.mec.gov.br/cne/ arquivos/pdf/rces003_05.pdf. Acesso em: 20 jan. 2018.

BUCKLAND, M. The landscape of information science: The American Society for Information Science at 62. Journal of the Association for Information Science and Technology, v. 50, n. 11, p. 970, 1999. Disponível em: https:// search.proquest.com/docview/231489426?pq-origsite=gscholar. Acesso em: 23 jan. 2018.

COORDENAÇÃO DE APERFEIÇOAMENTO DE PESSOAL DE NÍVEL SUPERIOR - CAPES. Avaliação Quadrienal Engenharias IV CAPES 2017. 2017. Disponível em: http://capes.gov.br/images/stories/download/avaliacao/relatorios-finais-quadrienal-2017/ 20122017-ENGENHARIAS-IV-quadrienal. pdf. Acesso em: 22 jan. 2018. 
COORDENAÇÃO DE APERFEIÇOAMENTO DE PESSOAL DE NÍVEL SUPERIOR - CAPES. Cursos Recomendados/

Reconhecidos. 2018a. Disponível em: http:// www.capes.gov.br/cursos-recomendados. Acesso em: 22 jan. 2018.

COORDENAÇÃO DE APERFEIÇOAMENTO DE PESSOAL DE NÍVEL SUPERIOR - CAPES. História e missão. $2018 b$. Disponível em: http://www.capes.gov.br/historia-e-missao. Acesso em: 22 jan. 2018.

COSTA, P. J. S. Gestão do Conhecimento em Organizações de Saúde: um conceito indispensável para a gestão em enfermagem. Revista Portuguesa de Gestão \& Saúde, Portugal, n. 21, p. 26-28, 2017. Disponível em: http://spgsaude.pt/website/wp-content/uploads/2017/05/ rpgs021.pdf\#page $=26$. Acesso em: 25 jan. 2018.

COSTA, R. T.; VIANA, I. A. F. Introdução aos Fundamentos Teóricos da Assessoria Secretarial: as vertentes funcionais desta atividade, sob a visão holística da profissão de secretariado. Revista de Empreendedorismo, Inovação e Tecnologia, Passo Fundo, v. 3, n. 2, p. 31-40, 2016. Disponível em: https://seer.imed.edu. br/index.php/revistasi/article/view/1069/917. Acesso em: 23 jan. 2018.

DAVENPORT, T. H. Process innovation: reengineering work through information technology. Harvard Business Press. [S.l.: s.n.], 2013.

FREITAS, S. F. T. Mais algumas notas sobre a transição da pós-graduação brasileira. Revista Brasileira de Pós-Graduação, Brasília, v. 8, n. 15, p. 19-32, 2011. Disponível em: http:// ojs.rbpg.capes.gov.br/index.php/rbpg/article/ view/209/pdf. Acesso em: 13 fev. 2018

GARFIELD, E. From scribes to secretaries in 5000 years; from secretaries to information managers in 20. Current Contents, v. 9, n. 15, p. 3-8, 1986.

GIL, A. C. Como Elaborar Projetos de Pesquisa. São Paulo: Editora Atlas, 2002. Disponível em: http://www.urca.br/itec/images/pdfs/ modulo $\% 20 \mathrm{v} \% 20 \% 20$ como elaborar projeto_de_pesquisa_-_antonio_carlos_gil.pdf. Acesso em: 26 jan. 2018 .

GILES, L.; VALLE, L.I.; PERRYMAN, S. A New Deal for Secretaries? Institute for Employment Studies, Report 313. University of Sussex. Brighton, UK: BEBC Distribution, 1996.

HOUSE, E. R. Tendencias en evaluación. Revista de Educación, v. 299, n. 1, p. 43-55, 1992.

LE COADIC, Y. A Ciência da Informação. Tradução Maria Yêda F. S. de Filgueiras Gomes. Brasília: Briquet de Lemos. 1996. Disponível em: http://www.restaurabr.org/siterestaurabr/CICRAD2011/M1\%20Aulas/M1 A3\%20 Aul/20619171-le-coadic-francois-a-ciencia-da-informacao.pdf. Acesso em: 25 jan. 2018.

MACCARI, E. A. et al. Sistema de avaliação da pós-graduação da Capes: pesquisa-ação em um programa de pós-graduação em Administração. Revista Brasileira de Pós-graduação. Brasília, v. 5, n. 9, p. 171-205, dez. 2008. Disponível em: http://ojs.rbpg.capes.gov.br/index. php/rbpg/article/view/147/141. Acesso em: 16 jun. 2017.

MACCARI, E. A. et al. A Gestão dos Programas de Pós-Graduação em Administração com base no Sistema de Avaliação da CAPES. Revista de Gestão - USP, São Paulo, v. 16, n. 4, p. 1-16, 2009. Disponível em: https://www. revistas.usp.br/rege/article/view/36682. Acesso em: 3 dez. 2020.

MACCARI, E. A. et al. Proposta de um modelo de gestão de programas de pós-graduação na área de Administração a partir dos sistemas 
de avaliação do Brasil (CAPES) e dos Estados Unidos (AACSB). Revista de Administração, São Paulo, v. 49, n. 2, p. 369-383, 2014. Disponível em: http://www.revistas.usp.br/rausp/ article/view/86392/89066. Acesso em: 22 jan. 2018 .

MAÇANEIRO, M. B.; CATCZU, T. S.; KORCHAQUE, E. L. Assessoria Executiva na Padronização e Organização de Processos Administrativos. Revista de Gestão e Secretariado, São Paulo, v. 3, n. 1, p. 109-133, 2012. Disponível em: https://www.revistagesec.org.br/secretariado/article/view/88. Acesso em: 24 jan. 2018.

MARCONI, M. A.; LAKATOS, E. M. Metodologia Científica. 5. ed. São Paulo: Atlas, 2008. Disponível em: https://docente.ifrn.edu. br/olivianeta/disciplinas/copy_of_historia-i/ historia-ii/china-e india. Acesso em: 11 abr. 2017.

MARTINS, C. B et al. Prováveis influências do primeiro ano do curso de Secretariado Executivo Bilíngue no cotidiano dos estudantes. Revista de Gestão e Secretariado, São Paulo, v. 1, n. 2, p. 53-77, jul./dez. 2010. Disponível em: http://www.redalyc.org/ pdf/4356/435641686004.pdf. Acesso em: 14 fev. 2018.

MARTINS, C. B.; MACCARI, E. A. Desempenho dos programas de pós-graduação stricto sensu em Administração, Ciências contábeis e Turismo no Brasil. Jundiaí: Paco Editorial, 2015.

MARTINS, J. B. Observação Participante: uma abordagem metodológica para a psicologia escolar. Semina: Ci. Sociais/Humanas, Londrina, v. 17 , n. 3, p. 266-273, set. 1996. Disponível em: https://www.researchgate.net/profile/ Joao_Martins6/publication/272653262_Observacao_participante_uma_abordagem_metodologica_para_a_psicologia_escolar/links/56f95c1008ae81582bf43830/. Acesso em: 29 jan.
2018.

MONTEIRO, C.; CECATTO, Q. C.; GARDIN, D. A. O. O Profissional de Secretariado e a Responsabilidade Socioambiental: a importância da assessoria executiva. Revista de Gestão e Secretariado, São Paulo, v. 6, n. 2, p. 134157, maio./ago. 2015. Disponível em: https:// www.revistagesec.org.br/secretariado/article/ view/359/pdf_74. Acesso em: 26 jan. 2018.

MONTEZANO, N. S.; SOUZA, R. B.; BAETA, O. V. A Importância da Gestão da Informação para a Atuação Profissional do Secretário Executivo: uma revisão de literatura nacional integrativa. Revista de Gestão e Secretariado, São Paulo, v. 6, n. 2, p. 111-133, maio./ ago. 2015. Disponível em: https://www.revistagesec.org.br/secretariado/article/view/356/ pdf_72. Acesso em: 28 jan. 2018.

MORAES, C. R. B.; FADEL, B. A Informação no Contexto Organizacional: tipos, características e usos. Revista de Sistemas de Información e Documentación - IBERSID, Espanha, p. 61-65, 2009. Disponível em: https://www.ibersid.eu/ojs/index.php/ibersid/article/view/3724. Acesso em: 5 fev. 2018.

MOREIRA, K. D. et al. As Competências Contemporâneas do Secretário Executivo e a Relação Com as Competências do Middle Manager. Revista de Gestão e Secretariado, São Paulo, v. 7, n. 1, p. 45-66, 1 abr. 2016. Disponível em: https://www.revistagesec.org.br/secretariado/ article/view/400. Acesso em: 25 jan. 2018.

NONATO JÚNIOR, R. Epistemologia e teoria do conhecimento em secretariado executivo: a fundação das ciências da assessoria. Fortaleza: Expressão gráfica, 2009.

OLIVEIRA, R. T. Q. et al. Os programas de pós-graduação stricto sensu no contexto das avaliações CAPES e CNPq. In: CONGRESSO NACIONAL DE EXCELÊNCIA EM GESTÃO, 4., 2008, Rio de Janeiro. Anais [...]. Rio 
de Janeiro, 2008. Disponível em: http://www. inovarse.org/filebrowser/download/8753. Acesso em: 16 jun. 2017.

PITASSI, C.; MORENO JÚNIOR, V. A. O papel das disciplinas de sistemas de informação nos cursos de graduação em administração. Administração: Ensino e Pesquisa, v. 10, n. 2, p. 9-32, 2009. Disponível em: https://raep. emnuvens.com.br/raep/article/view/191/154. Acesso em: 16 jan. 2018.

REGINATO, C. E. R.; GRACIOLI, O. D. Gerenciamento Estratégico da Informação por meio da Utilização da Inteligência Competitiva e da Gestão do Conhecimento - um estudo aplicado à indústria moveleira do RS. Revista Gestão e Produção, São Carlos, v. 19, n. 4, p. 705-716, 2012. Disponível em: http://www. scielo.br/pdf/gp/v19n4/a04v19n4.pdf. Acesso em: 25 jan. 2018.

REZENDE, D. A. Digital City: Chicago and Schaumburg (USA) information, sustainability indicators and public services projects. Revista de Gestão e Secretariado, São Paulo, v. 7, n. 2, p. 55-79, maio/ago. 2016. Disponível em: https://www.revistagesec.org.br/secretariado/ article/view/545/pdf. Acesso em: 26 jan. 2018.

RODRIGUES, L. M.A.; LAVARDA, R. A. B.; MARTINS, C. B. O profissional de secretariado executivo: gestor de informações no processo de formação da estratégia. Revista Capital Científico-Eletrônica (RCCee), v. 15, n. 3, p. 126-142, 2017. Disponível em: https://revistas. unicentro.br/index.php/capitalcientifico/article/view/4772. Acesso em: 4 dez. 2020.

ROESCH, M. S. A. Projetos de estágio e de pesquisa em administração: guia para estágios, trabalhos de conclusão, dissertações e estudos de caso. São Paulo: Atlas S.A., 2009.

SANTOS, A. S. et al. Atuação do Psicólogo Escolar e Educacional no ensino superior: reflexões sobre práticas. Revista Psico- logia Escolar e Educacional, v. 19, n.3, p. 515-524, 2015. Disponível em: http://www. scielo.br/scielo.php?script $=$ sci_arttext\&pi$\mathrm{d}=\mathrm{S} 141385572015000300515 \& \operatorname{lng}=$ en\&nr$\mathrm{m}=$ iso. Acesso em: 16 jun. 2017.

SILVA, E. L.; MENEZES, E. M. Metodologia de Pesquisa e Elaboração de Dissertação. 2005. Disponível em: http://200.17.83.38/portal/upload/com_arquivo/metodologia_da_pesquisa_e_elaboracao_de_dissertacao.pdf. Acesso em: 19 mar. 2017.

SOARES, S. A. S.; PAULY, E. L. A Atuação dos(as) Secretários(as) na Gestão dos Programas de Pós-Graduação stricto sensu do Sul do Brasil. Revista Gestão e Secretariado - GESEC, São Paulo, v. 9. n. 2, p. 20-44, maio/ago. 2018. Disponível em: https://www.revistagesec.org.br/secretariado/article/view/666. Acesso em: 4 dez. 2020.

TRIVIÑOS, A. N. S. Introdução à pesquisa em ciências sociais: pesquisa qualitativa em educação. São Paulo: Atlas S.A., 2010.

UNIVERSIDADE FEDERAL DE SANTA CATARINA. Ofício Circular no 015/2005/ CGGP/SAA/SE/MEC, de 28 de novembro de 2005. Trata da descrição de cargos técnico-administrativos em educação. 2005. Disponível em: http://prodegesp.ufsc.br/files/2010/03/ Oficio015-2005MEC.pdf. Acesso em: 13 fev. 2018.

UNIVERSIDADE FEDERAL DE SANTA CATARINA. Resolução Normativa N. 95/ CUn/2017. Dispõe sobre a pós-graduação stricto sensu na Universidade Federal de Santa Catarina. 2017. Disponível em: http://temppgeas.paginas.ufsc.br/files/2017/08/RN95_P\%C3\%B3sGradua $\%$ C3\%A7\%C3\%A3o_stricto_ sensu.pdf. Acesso em: 31 jan. 2018.

UNIVERSIDADE FEDERAL DE SANTA CATARINA. Programas de Pós-Graduação. 2018a. Disponível em: http://propg.ufsc.br/ 
cap/programas-de-pos-graduacao/. Acesso em:

22 jan. 2018.

UNIVERSIDADE FEDERAL DE SANTA CATARINA. Programa de Pós-Graduação em Engenharia de Automação e Sistemas (2018b).

VAN DAMME, D. Internationalization and quality assurance: towards worldwide accreditation? European Journal for Education Law \& Policy, v. 4, n. 1, p. 1, 2000.

VERGARA, S. C. Projetos e relatórios de pesquisa em administração. São Paulo: Atlas S.A., 2007. 